\title{
Virtuele vrouwen : constructies van gender online
}

Citation for published version (APA):

van Zoonen, L. (2000). Virtuele vrouwen : constructies van gender online. Universiteit Maastricht. https://doi.org/10.26481/spe.20000526lz

Document status and date:

Published: 26/05/2000

DOI:

$10.26481 /$ spe.20000526lz

Document Version:

Publisher's PDF, also known as Version of record

\section{Please check the document version of this publication:}

- A submitted manuscript is the version of the article upon submission and before peer-review. There can be important differences between the submitted version and the official published version of record.

People interested in the research are advised to contact the author for the final version of the publication, or visit the DOI to the publisher's website.

- The final author version and the galley proof are versions of the publication after peer review.

- The final published version features the final layout of the paper including the volume, issue and page numbers.

Link to publication

\footnotetext{
General rights rights.

- You may freely distribute the URL identifying the publication in the public portal. please follow below link for the End User Agreement:

www.umlib.nl/taverne-license

Take down policy

If you believe that this document breaches copyright please contact us at:

repository@maastrichtuniversity.nl

providing details and we will investigate your claim.
}

Copyright and moral rights for the publications made accessible in the public portal are retained by the authors and/or other copyright owners and it is a condition of accessing publications that users recognise and abide by the legal requirements associated with these

- Users may download and print one copy of any publication from the public portal for the purpose of private study or research.

- You may not further distribute the material or use it for any profit-making activity or commercial gain

If the publication is distributed under the terms of Article $25 \mathrm{fa}$ of the Dutch Copyright Act, indicated by the "Taverne" license above, 
MB VAA 075

Virtuele vrouwen: tructies van gender online

Prof. dr. Liesbet van Zoonen

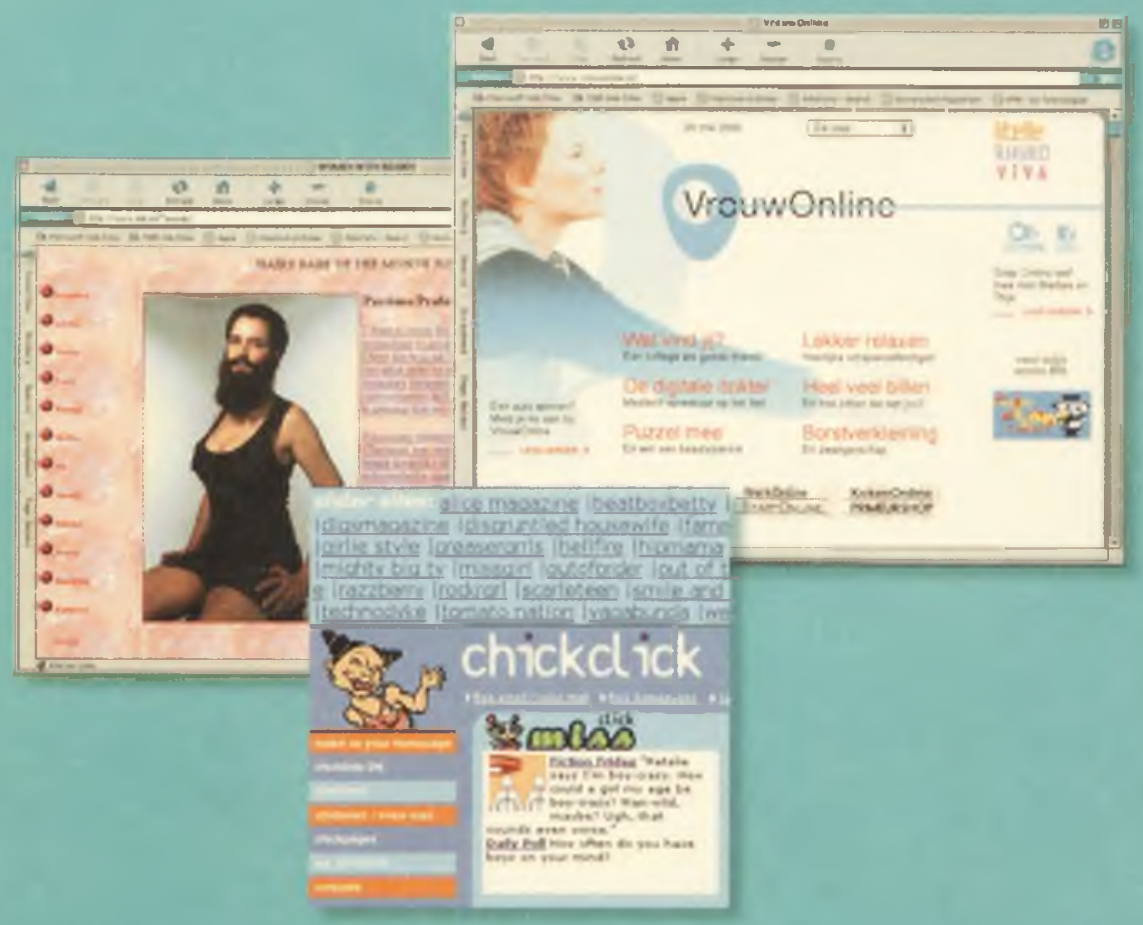

M Universiteit Maastricht 


\title{
Virtuele vrouwen: \\ 075 \\ constructies van gender online
}

$V A A$

\author{
Liesbet van Zoonen
}

\section{Rede}

In verkorte vorm uitgesproken bij de aanvaarding van het ambt van bijzonder hoogleraar vanwege het feministisch maandblad Opzij - Macht en strategie: gender en multimedia - en het ambt van gewoon hoogleraar vrouwen- en genderstudies aan de Universiteit van Maastricht op vrijdag 26 mei 2000

door

Prof.dr. E.A. (Liesbet) van Zoonen

Universiteit Maastricht

Centrum voor Gender en Diversiteit 
197286836

Abonn

2 
Mijnheer de Rector Magnificus, dames en heren,

Het is een grote eer en een grote uitdaging om vandaag het ambt van hoogleraar te aanvaarden. Een grote eer omdat het niet zomaar om een leerstoel gaat, maar om een leerstoel die is ingesteld door het maandblad Opzij, het oudste, grootste en belangrijkste feministische blad van Nederland. Een leerstoel die bovendien gevestigd is bij het Centrum voor Gender en Diversiteit van de Universiteit Maastricht, waar ik mag werken met gerenommeerde collega's als Maaike Meijer en Mineke Bosch. Het is een grote uitdaging omdat de leerstoel beschikbaar is voor één dag in de week gedurende een periode van twee jaar. lemand rekende mij laatst voor dat dat exclusief vakantie op ongeveer tachtig dagen neerkomt. Dat lijkt niet zoveel, maar als Jules Verne in tachtig dagen de wereld rond kon, zou $i k$ in tachtig dagen het onderwerp gender en multimedia op de wetenschappelijke en maatschappelijke agenda moeten kunnen zetten. Dat is althans wat ik mij voorgenomen heb, en in de komende drie kwartier zal ik u daar meer over vertellen. 


\section{Inleiding}

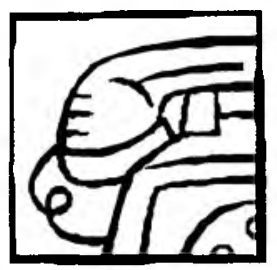

Om te beginnen wil ik $u$ vragen u zich de beginjaren van de telefoon voor te stellen. Aan het eind van de negentiende eeuw werd de telefoon in de Verenigde Staten op de markt gebracht. De technologie stond nog in de kinderschoenen: er waren nog heel weinig abonnees en je had nog telefonistes nodig om gesprekken door te verbinden. De Bell Telephone Company, vernoemd naar de uitvinder van de telefonie Alexander Graham Bell, was marktleider - als je dat al zo mocht noemen - maar er waren talloze kleinere, lokale bedrijven die Bell beconcurreerden. In die situatie vroeg één van de kleine telefoonmaatschappijen in Indiana een openbare hoorzitting aan over aanvaardbaar gebruik van de telefoon. Het bedrijf probeerde bezwaar te maken tegen de manier waarop veel vrouwen de telefoon gebruikten: vrouwen hielden lange gesprekken over onbelangrijke zaken en daar was de telefoon niet voor bedoeld, zo beweerde de Indiana Telephone Company (Rakow, 1988). Het bedrijf had in zoverre gelijk dat de telefoon tot dan toe geïntroduceerd en voorgesteld was als een medium voor praktisch, zakelijk verkeer, enigszins vergelijkbaar met de telegraaf. Kleine middenstanders en zakenlieden vormden de eerste belangrijke doelgroep. Op tentoonstellingen, in advertenties en door telefoonverkopers werd er onophoudelijk de nadruk op gelegd dat de telefoon de efficiëntie zou vergroten, tijd zou besparen en indruk zou maken op klanten (Fischer, 1992: 66). Veel vrouwen, echter, hadden een andere opvatting over de telefoon en gebruikten het nieuwe medium voor wat we tegenwoordig 'sociale doeleinden' zouden noemen. $V$ ia de telefoon onderhielden vrouwen de contacten met familie en vrienden, en wisselden ze de laatste nieuwtjes en ervaringen uit. De leiders van de snel groeiende telefoonindustrie probeerden op allerlei manieren dat soort gebruik van de telefoon te voorkomen. Ze beschouwden dergelijk 'geklets' aan de telefoon als het zoveelste bewijs van vrouwelijk onvermogen en dommigheid (Fischer, 1992:231). In de kranten van die tijd verschenen klachten (Martin, 1988:96); in de populaire literatuur ontstond een makkelijk herkenbaar beeld van eindeloos telefonerende vrouwen, bijvoorbeeld in een drie pagina's lange sketch van Mark Twain, A telephone conversation (Brooks, 1977). In die context is het begrijpelijk dat de Indiana Telephone Company een openbare hoorzitting nodig achtte om het telefoongedrag van vrouwen te disciplineren. Er lag natuurlijk ook een simpel financieel motief aan ten grondslag: de telefoonrekening bestond uit kosten per gesprek en was nog niet afhankelijk van de lengte van de gesprekken. Op de hoorzitting bleek echter al snel dat de doorsnee 
telefoongebruiker geen enkel bezwaar had tegen de manier waarop vrouwen het medium gebruikten.

De verantwoordelijke commissie van de staat Indiana besloot daarom dat ze geen reden zag om ertegen op te treden (Rakow, 1988:220). Het duurde natuurlijk niet lang voordat de telefoonindustrie begreep dat in het telefoongebruik van vrouwen grote winsten lagen. Zo rond de jaren twintig van deze eeuw verschoof de industriële voorstelling van de telefoon als een praktisch middel naar een beeld van de telefoon als een medium voor gemak, contact en conversatie (Fischer, 1992).

Tegenwoordig kunnen we ons de telefoon eigenlijk niet meer anders voorstellen dan als een middel om sociale contacten te onderhouden. We kunnen daarom alleen maar concluderen dat vrouwen grotendeels verantwoordelijk zijn geweest voor de telefooncultuur zoals we die vandaag de dag kennen (Martin, 1991:171, aangehaald in Fischer, 192:236).

\section{Vraagstelling}

Tussen de opkomst van de telefoon en de opkomst van het Internet zitten ruim negentig jaar. Toch is het op talloze manieren maar een kleine stap van de telefoon naar het Internet. Het Internet dataverkeer loopt grotendeels via telefoonverbindingen, om maar iets heel simpels te noemen. De grote nationale en internationale telecombedrijven zijn met elkaar in een miljardenslag om de exploitatie van het Internet. Net als de telefoon heeft het Internet zich ontwikkeld van een medium van een kleine elite tot een medium voor alledaags gebruik. Er wordt van het Internet een even grote culturele invloed verwacht als van de telefoon is uitgegaan. Wat die invloed precies zal zijn, is onderwerp van hevige speculatie in wetenschap en media, maar weten doen we er nog niet zoveel over. Zoals het voorbeeld van de telefoon laat zien, krijgt een technologie vooral betekenis door de manier waarop ze gebruikt wordt en ingepast in het dagelijks leven. Al kunnen we van Internet nog nauwelijks zeggen dat het ingebed is in het dagelijks leven, toch zijn er al tal van verwachtingen daarover, en een belangrijke daarvan is dat ook de Internetcultuur uiteindelijk door vrouwen bepaald zal worden. Die verwachting vormt vandaag mijn rode draad waaraan ik meteen de vraag koppel die in de leeropdracht van deze Opzij Leerstoel Gender en Multimedia gesteld wordt (ik citeer): "Biedt het Internet een 'nieuwe kans' voor een herformulering van gender, of zetten 'oude verhoudingen' zich onverminderd door?" Gaandeweg kondig ik dan ook de onderzoeksagenda aan die ik als Opzij Hoogleraar zou willen realiseren. 


\section{Internetcultuur, vrouwen en vrouwelijkheid}

U bent misschien verbaasd over de suggestie dat de Internetcultuur uiteindelijk door vrouwen bepaald zal worden. U denkt misschien: "Maar dat Internet wordt toch gedomineerd door mannen?" En dat is ook zo. Het zogenaamde actornetwerk dat we kunnen onderscheiden in de ontwikkeling van het Internet is bijna $100 \%$ mannelijk geweest, zowel in termen van de menselijke actoren die erbij betrokken waren als in termen van de verschillende technische actoren, $\mathrm{u}$ moet bij dat laatste dan aan de hard- en software denken. Onder de diverse Internetuitvinders en ingenieurs vinden we pas midden jaren tachtig een vrouw - Nicola Pellow -, zij was betrokken bij de ontwikkeling van HTML, de programmeertaal die het World Wide Web mogelijk maakte (Naughton, 1999). In die situatie zal geen verandering komen, sterker nog: in de VS is het aantal vrouwen dat in de IT-sector werkt teruggevallen van $30 \%$ in 1989 tot $15 \%$ vandaag de dag (Nua, 1998). Ook neemt het aantal vrouwen in IT-opleidingen af. Naast het actornetwerk achter het Internet, wordt ook datgene wat we aan teksten, beelden, connecties en relaties op het Internet vinden eerder door mannen dan door vrouwen gedomineerd, en dan vooral door mannelijke narigheid. Gewone porno en kinderporno, seksuele intimidatie, rechts extremisme enzovoort, hebben het Internet de slechte reputatie gegeven waartegen momenteel tal van actiegroepen en overheden in het geweer komen. Het is wat dat betreft illustratief dat een belangrijke mondiale beweging van vrouwen op het Net, de zogenaamde Webgrrls, zichzelf "grrls" in plaats van "girls" hebben moeten noemen (Sherman, 1998). De zoeksleutel 'girls' levert namelijk vooral pornografische sites op. Tenslotte leidt een blik op de huidige gebruikers van het Internet ook niet onmiddellijk tot de gedachte dat de toekomst van het Internet vrouwelijk zal zijn. Volgens een publicatie uit december 1999 van het Sociaal Cultureel Planbureau zijn $28 \%$ van de Nederlandse mannen online, tegenover $14 \%$ van de Nederlandse vrouwen (SCP, 1999). Uit onderzoek van de Nederlandse Internet Society van oktober 1999 blijkt bovendien dat mannen Internet vaker en intensiever gebruiken dan vrouwen (ISOC, 1999).

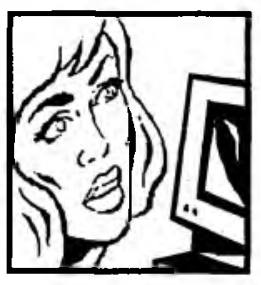

En toch zijn er mensen die beweren dat de toekomstige cultuur van het Internet door vrouwen bepaald zal worden. Aan de ene kant zijn dat sommige feministische wetenschapsters, aan de andere kant zijn het kapitalistische marketeers. Om met die wetenschapsters te beginnen. De Amerikaanse Sherry Turkle, hoogleraar in de wetenschapssociologie aan het 
gezaghebbende Massachussetts Institute of Technology, het MIT, stelt bijvoorbeeld dat het bij het World Wide Web en het Internet gaat om gemeenschappelijkheid en om samenwerking, om wie in staat is consensus te vormen. Dat zijn de benodigde vaardigheden, aldus Turkle en vrouwen kunnen die op tafel leggen (in Jenkins, 1999:332). De Britse techniek historica Sadie Plant, in de Engelse pers opgehemeld als de beste en meest radicale 'technotheorist' ziet een vergelijkbaar vrouwelijk element in het Internet: "Ondanks of misschien wel dankzij het onpersoonlijke beeldscherm, maakt de digitale zone onvermoede niveaus van spontane affectie, intimiteit and informaliteit mogelijk en daarmee wordt duidelijk zichtbaar hoe oude media, met name datgene dat we als het echte leven aanduiden, vol zitten met remmingen, grenzen en hindernissen." (Plant, 1998:144). En ook de Australische taalwetenschapster Dale Spender zegt in haar boek Nattering on the Net dat het Internet bij uitstek geschikt voor vrouwen en andere minderheidsgroepen zou zijn (1995). In de argumentaties van Turkle, Spender en Plant vallen vrouwen, communicatie, consensus, affectie en intimiteit samen en we herkennen daar een notie van vrouwelijkheid in die zowel voor traditionele als voor feministische doeleinden ingezet wordt. Het is een notie van vrouwelijkheid waar vrouwen zowel mee op hun plaats gehouden zijn (vrouwen laten zich leiden door gevoelens) als waarmee vrouwen hun superioriteit geclaimd hebben (vrouwen zijn veel beter met gevoelens) - om het allemaal wat kort door de bocht te zeggen. In beide gevallen wordt vrouwelijkheid nogal essentialistisch gedefinieerd: communicatie, consensus, affectie, intimiteit en gevoeligheid horen bij vrouwen en al geven genoemde auteurs daar een positieve draai aan, essentialistisch (zo zijn vrouwen) blijft het.

Een zelfde verhaal over vrouwen, zij het met een andere inspiratiebron, vinden we bij dat andere deel van het gezelschap, de kapitalistische marketeer. It's a woman's world meldde een interactief marketingbureau in november van vorig jaar over het Internet (VODW, 1999). Op basis van Amerikaanse gegevens waaruit zou blijken dat het aantal vrouwen online in Amerika groter is dan mannen, concludeerde het bureau dat daarmee ook in Nederland grote kansen ontstaan voor het bedrijfsleven, immers in de fysieke offline wereld kopen vrouwen $80 \%$ van alle huishoudelijke producten, en regelen ze in $75 \%$ van de gevallen de financiën. Om vrouwen op het Internet goed te kunnen bedienen, moeten bedrijven rekening houden met de verschillende manieren waarop mannen en vrouwen online opereren. Vrouwen, zo blijkt uit het onderzoek, zouden een hogere behoefte hebben aan interactiviteit dan mannen, gebruiken vaker e-mail, bezoeken vaker discussiegroepen, hebben veel behoefte aan 
ideeënuitwisseling en bevestiging, meer behoefte aan persoonlijk contact, ze vinden een 'persoonlijke' relatie met de site belangrijk en ze voelen zich sterk verbonden met online gemeenschappen. De communicatie, consensus en intimiteit die Turkle, Spender en Plant ons dus vanuit een feministisch theoretisch perspectief voorspiegelden, lijkt te worden ondersteund door de harde cijfers van de kapitalistische marketing waaruit blijkt dat vrouwen met name de communicatieve en persoonlijke toepassingen van het Internet waarderen; feminisme (althans een deel daarvan) en kapitalisme gaan ineens hand in hand als het om de koppeling van vrouwen, vrouwelijkheid, communicatie en het Internet gaat en dat levert een tamelijk traditioneel plaatje op. De verwachting dat de cultuur van het Internet door vrouwen bepaald zal worden, is in deze context dan ook niet zonder meer om vrolijk van te worden, omdat met name traditionele, eendimensionale opvattingen van vrouwelijkheid aan het Internet gekoppeld worden.

\section{Tegengas}

Er valt gelukkig wel iets tegen dit traditionele plaatje in te brengen: ten eerste kloppen de redeneringen erachter niet: noch de redenering van de genoemde feministische auteurs, noch die van de marketeers. Ten tweede is de praktijk van het Internet veel weerbarstiger dan het traditionele plaatje doet vermoeden. Ik begin met de redeneringen: op anekdotisch niveau kunnen we al zien dat de gedachte dat vrouwen zo goed zouden zijn in samenwerking en communicatie op het net, veel weerstand oproept onder vrouwen. Een nijdige Grrl Gamer zegt bijvoorbeeld:

"Community and collaboration are what women bring to the table? God, that is so 1950s, so retro, so family and hearth and Donna Reed. We're good little community makers and collaborators. We don't ever really do anything ground breaking, just create nice little places to live and work and raise our babies! That's what women are good at! If we work together we can all be friends. Well, screw that! I don't want to be friends! I want to be King! That's right, King, Hail to the King, baby! I want all the best stuff and I want it all for me and I will knock the hell out of anyone who tries to take a piece of my action. Not very community driven and collaborative, am I? (Jenkins, 1999:332).

Maar we kunnen de verbinding Internet $=$ communicatie $=$ vrouwen $=$ vrouwelijkheid ook op een meer theoretische grondslag proberen te ontmantelen. Over de problemen van een essentialistische opvatting over 
vrouwelijkheid hoef ik het in dit gezelschap niet uitgebreid te hebben, daar is decennia lang uitgebreid debat in de Nederlandse vrouwenstudies over gevoerd (Hermsen en Van Lenning, 1991). Waar ik wel op wil wijzen is dat Plant, Spender en Turkle hun uitspraken baseren op een evaluatie van de technologische kenmerken en mogelijkheden van het Internet. In de terminologie van de communicatiewetenschap zouden we zeggen dat ze hun analyse baseren op de eigenschappen van de tekst, en niet op de wijze waarop die tekst betekenis krijgt in de interactie met lezers en het alledaagse leven (bv. Moores, 1993). In termen van technologie studies zouden we zeggen dat deze auteurs de zogenaamde consumption junction (Schwartz Cowan, 1987) overslaan, dat wil zeggen de manier waarop gebruikers zich bepaalde technologieën toe-eigenen en een plaats geven in hun dagelijks leven. Zowel in de communicatiewetenschap als in technologiestudies komt een dergelijke gelimiteerde focus op de tekst of technologie zelf steeds minder voor, en wordt aan lezers, kijkers of gebruikers een doorslaggevende rol toegekend in de constructie van de culturele betekenis van een tekst of technologie (bv. Silverstone \& Hirsch, 1992). De culturele betekenis van het Internet moeten we dan ook zoeken in de manier waarop het gebruikt wordt en de betekenis die gebruikers en gebruiksters eraan geven. En de stelling dat de Internetcultuur door vrouwen bepaald zal worden, moet dus door de gebruikspraktijk ondersteund worden. Als van de 100 gebruiksters er 99 King willen zijn, bij wijze van spreken en alles voor zichzelf willen, zoals de Game Grrl die ik eerder aanhaalde, vervalt de vrouwelijke betekenis van het Internet als een Eldorado van communicatie en intimiteit.

Maar dat is een hypothetisch geval, zult u zeggen, want de kapitalistische marketeer heeft toch met de eerder genoemde onderzoeken aangetoond dat de meeste vrouwen dat Internet gebruiken of willen gebruiken voor persoonlijke contacten en uitwisseling. Dat gegeven is zelfs zo overtuigend dat momenteel talloze e-commerce strategieën erop gebaseerd worden. Het marktonderzoek lijkt ons daarmee een dwingende waarheid op te leggen over de kenmerken van de vrouwelijke Internetgebruiker. $\mathrm{Er}$ is echter ook marktonderzoek dat zegt dat vrouwen het Internet zo doelgericht mogelijk gebruiken en er vooral tijd mee willen besparen. Vrouwen blijken ook veel minder lang online te zijn dan mannen (Nua, 2000). Dat zijn gegevens die zich slecht verhouden met de veronderstellende vrouwelijke voorkeuren voor persoonlijk contact, uitwisseling en chatten; dat zijn activiteiten die nogal wat tijd kosten. Die tegenstrijdigheid in de onderzoeksresultaten heeft ongetwijfeld te maken met het feit dat er nog nauwelijks een algemeen geaccepteerde standaard is met betrekking tot de manier waarop onderzoek gedaan moet 
worden naar de Internetgebruikers.' Door de variëteit aan onderzoeksmethoden ontstaat er ook een variëteit aan resultaten waarbij sommige resultaten meer aandacht en status verwerven dan andere, en dat zijn nu precies de resultaten die aansluiten bij algemeen gedeelde traditionele opvattingen over vrouwelijkheid. Het is niet toevallig dat een deelnemer aan een Amerikaans panel over Internet marketing die beweerde dat er geen verschil was tussen mannen en vrouwen online, met hoon overladen werd, terwijl zijn stelling dat zowel mannen als vrouwen van een site verwachten dat deze snel, eerlijk en betrouwbaar is, en dat de site - zogezegd - 'luistert', toch niet zo onwaarschijnlijk was.

Maar zelfs als er over een jaar of tien een standaardmethode zou zijn in de Internetmarketing waar consistente resultaten over man-vrouwverschillen op het Net uitkomen, dan nog kunnen we die gegevens niet zomaar als 'waar' beschouwen. Ze kunnen om te beginnen slechts geldig zijn voor een heel klein deel van het leven, namelijk dat deel waarin we consumeren. Niet voor niets heet een van de veel aangehaalde studies uitgevoerd door Women.com Networks, Harris Interactive en Procter \& Gamble: The Online Woman. How to Tap into her buying power (Nua, 1999). Hoe vrouwen zich als burger op dat net gedragen, of als werknemer, of als activist, of als hobbyist, of als intellectueel, om maar wat te noemen..., dat valt allemaal buiten die consumentenrol, dat weten we dus niet. Een fundamenteler probleem heeft te maken met wat len Ang (1991) de institutionele epistemologie van dergelijk onderzoek heeft genoemd. In haar boek Desperately secking the audience beschrijft ze hoe het onderzoek naar televisiekijkgedrag ingebed is in institutionele verhoudingen en vereisten. De resulterende kijkcijfers en demografieën van kijkers zijn vooral nuttig voor beleidsmakers binnen de televisieindustrie maar leveren weinig kennis op over wat Ang noemt "de dynamische complexiteit van de sociale wereld van daadwerkelijke publieken." (p. 155). Sterker nog: volgens Ang kunnen we het televisiepubliek nooit in zijn geheel begrijpen, maar moeten we ons neerleggen bij het feit dat de sociale wereld van daadwerkelijke publieken bestaat uit een oneindige en zich steeds uitbreidende waaier van uiteenlopende praktijken en ervaringen waarvan we met onderzoek slechts kleine gedeeltes in kaart kunnen brengen. Voor het marketingonderzoek naar Internetgebruikers geldt hetzelfde als voor het kijkcijferonderzoek maar dan nog in veel extremere mate.

' Een gezaghebbend bedrijf in de VS, Nielsen Netratings, werkt met telefonische interviews, maar de Nederlandse Summo Webprofiler, die de ambitie heeft on dezelfde status te venwenen als de Summo Scanner heeft in de tijdschriftenindustrie, baseert zijn resultaten op data die op de Intennetpagina's zelf verzameld worden. De Nationale Internet Monitor van Adformatie en Proactive, werkt weer met email en vragenlijsten op sites. 
Internetgebruikers kunnen uit een aanbod kiezen dat miljoenen keer zo groot is als het televisieaanbod, en daar niet alleen gebruik van maken (naar kijken in televisietermen), maar ook nog zelf iets aan toevoegen. De aard van het Internet leidt tot een fragmentatie van publieken, publieksgedrag en publiekservaringen die onmogelijk door wat voor overkoepelend, representatief onderzoek dan ook gevangen kan worden. De gebruikspraktijk van het Internet is veel weerbarstiger dan de eendimensionale schema's van het marktonderzoek en van sommige feministische auteurs. Hoe kunnen we die vele barsten en scheuren van die gebruikspraktijk dan in kaart brengen?

\section{Gender scripts}

De communicatiewetenschap suggereert twee manieren: men kan nagaan welke gebruikers door een site of door een verzameling sites verondersteld worden. We spreken dan over de subjectpositie- of posities die door een tekst aangeboden worden; in slecht vertaalbare engelse termen hebben we het dan over implied audiences of spectators. De andere optie is om in kleinschalig, etnografisch georiënteerd zogenaamd receptieonderzoek te kijken wat het gebruik en de interpretaties van daadwerkelijke publieken zijn. ${ }^{2}$ Dergelijk etnografisch onderzoek over het Internet ben ik nog niet vaak tegengekomen, al zijn er in Nederland wel enkele projecten in voorbereiding en behoort het ook tot mijn eigen onderzoeksagenda, ik kom daar later nog op terug. Op dit moment kunnen we vanwege dat gebrek aan onderzoek alleen nog naar de veronderstelde gebruikers van het Internet kijken.

Het communicatiewetenschappelijke idee van de implied audience of de spectator vertoont conceptuele overeenkomsten met het idee van het technologische script dat afkomstig is uit de sociologie en geschiedenis van de techniek. Apparaten bevatten een bepaald script in de zin dat deze bepaalde handelingen, taken en verantwoordelijkheden suggereren aan gebruikers, met andere woorden, gebruikers zitten in feite in apparaten ingebouwd. Nelly Oudshoorn heeft dat scriptidee in haar oratie uitgewerkt naar gender: "Als in apparaten een bepaalde visie op de verschillen tussen vrouwen/vrouwelijkheid en mannen/mannelijkheid is ingebouwd, noemen we dit het genderscript van een technologie." (Oudshoorn,

\footnotetext{
: Aan de terminologie van publicken en receptic lezen we de herkomst van dergelijke benaderingen uit film-en televisiestudies. Voor het Internetonderzoek zijn de termen publiek en receptie eigenlijk te passief en negeren ze de actieve rol van Internetgebruikers in het samenstellen van hum eigen 'teksten' om het zo maar te zeggen - uit het bestaande aanbod, en in het toevoegen van Itum eigen informatie ch communicatie an het bestande aambod.
} 
1996:9). Wat voor genderscripts, wat voor suggesties voor de manier waarop mannen en vrouwen het Internet zouden moeten gebruiken, kunnen we nu op dat Internet aantreffen? De beantwoording van die vraag is een enigszins hachelijke zaak omdat er inmiddels meer dan een miljard pagina's alleen al op het World Wide Web te vinden zijn die tot op zekere hoogte elk hun eigen kleine of grotere genderscript bevatten. Desalniettemin wil ik een paar algemene lijnen trekken. I $\mathrm{k}$ begin daar waar de meeste mensen het Internet binnen gaan: bij de startpagina van hun service provider. lk bespreek er hier twee die mijn argument precies illustreren: allereerst de allergrootste van Nederland, die van WorldAccess hoewel die positie op de ranglijst bestreden wordt door Worldonline - en dan een van de oudste, die van de Digitale Stad.

\section{Traditionele scripts}

Via het adres www.wxs.nl komen we op Planet Internet, een van de service providers van KPN. We zien allereerst een tamelijk doorsnee online nieuwspagina, met aan de bovenkant een aantal categorieën waar we naar door kunnen surfen, zoals business, computers, kids, living, movie en women. Zo'n indeling doet tegelijkertijd denken aan de gewone indeling van kranten met verschillende secties (al is in de meeste kranten de vrouwenpagina vervangen door zogenaamd breder georiënteerde lifestyle secties) maar ook, en misschien wel meer, aan de categorisering van bladen die we in de kiosk aantreffen. Die indruk van déja-vu wordt nog versterkt als we doorklikken op 'vrouwen': we arriveren op de women's planet en worden geconfronteerd met vrouwennieuws: "De nieuwe makeup van Lancome, en: "Nieuw: anti-cellulitis panty" (maandag 5 maart). We vinden opnieuw een aantal categorieën waar we op door kunnen

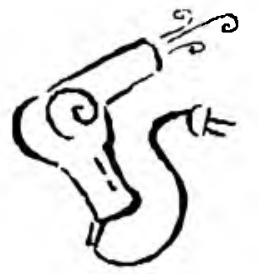
klikken, onder andere carrière culinair, gezin, leven, mode en beauty en weer 'vrouwen'. Men kan zich indenken wat die categorieën ongeveer zullen voorstellen, alleen onder het kopje Carrière treden we even buiten het kader van traditionele vrouwelijkheid dat de vrouwenplaneet in de andere gevallen omringt. Onder 'vrouwen' vinden we een diversiteit aan artikelen over en links naar andere vrouwensites, hele traditionele, maar ook enkele feministische. Ook treffen we hier de onvermijdelijke

\footnotetext{
"Bovendien is een grondige analyse van genderscripts gebaseerd op een analyse van de actornetwerken watarin een technologie geproduceerd wordt, de vooronderstellingen van de ontwerpers en de verschijningsvormen van de teclmologie (bv. Rommes et al., 1999).
} 
verwijzing naar de grootste vrouwensite op het net: de Amerikaanse women.com, een initiatief van twee vrouwen die nogal handig waren met het Internet. De site werd opgekocht door Yahoo en heeft inmiddels een zelfstandige notering op de NASDAQ de beurs voor technologiefondsen." De onlangs gestarte Nederlandse portal van VNU, Vrouw Online, is geheel en al gemodelleerd op dit Amerikaanse voorbeeld. De eerlijkheid gebiedt overigens te zeggen dat women.com naast de bekende traditionele onderwerpen en reclames ook een discussie aanzwengelt rond de Amerikaanse voorverkiezingen en wat voor individuele vrouwen de belangrijkste campagne-issues zouden moeten zijn; earn-my-vote heet dit bulletin board.

Het zal duidelijk zijn dat in deze voorbeelden een enorm traditioneel genderscript besloten zit dat we al kenden uit de wereld van de vrouwenbladen op papier. De in deze sites geconstrueerde vrouwelijke Internetgebruiker is vooral geïnteresseerd in gezin, huis, uiterlijk, carrière - ze is tenslotte wel van deze tijd - en soms wat politiek. Ze praat daar bovendien graag over met anderen. Dat beeld sluit niet toevallig naadloos aan bij de vrouwelijke Internetgebruiker die de marketeers ons schetsen. Dergelijke sites nodigen uit tot een bepaald soort gebruik en - eureka - uit marktonderzoek blijkt vervolgens dat vrouwen het Internet ook zo gebruiken of willen gebruiken. Dat lijkt verdacht veel op een self-fulfilling prophecy waar in elk geval de grote dot.com bedrijven en adverteerders garen bij spinnen. Maar of het nu ook klopt met wat vrouwen daadwerkelijk met het Internet doen en beleven, en of dat in alle contexten altijd hetzelfde is, is nog maar de vraag.

\section{Feministische scripts}

Op naar de volgende startpagina, die van de Digitale Stad, een van de eerste virtuele gemeenschappen, begonnen als experiment van hackers en gesubsidieerd uit overheidsgelden, inmiddels omgebouwd tot een service provider die in zijn eigen inkomsten moet voorzien (Rommes et al., 1999). We kennen onze weg in de Digitale Stad niet helemaal, dus kiezen we op de startpagina voor de optie 'Plattegrond'. Tussen de grote hoeveelheid icoontjes vinden we ook in paars het vrouwenteken waarachter het Vrouwenplein verborgen zit. Dat vrouwenteken suggereert een vrouwelijke

'De nieuwste aanwinst van women.com op dit gebied is eHarlequin.com, cen online gemeenschap van boeketlezers dic een scala aan chatmogelijkheden biedt, mast informatie over de boeken en online 'meet-the-author' sessies. 
gebruiker met feministische interesses en dat wordt bevestigd op het vrouwenplein: daar treffen we onder andere het Amsterdamse vrouwenhuis, verschillende netwerken voor zwarte en migrantenvrouwen en diverse instanties die zich met de emancipatie van vrouwen bezig houden. Op het prikbord staan tal van aankondigingen, begin maart vooral voor de vieringen van Internationale Vrouwendag, maar ook een aantal links naar andere feministische sites. Naast het plein, worden een aantal zijwegen aangegeven, kunnen we een café bezoeken (dat is Tinne's bar), en ons in discussiegroepen storten. De structuur van het Vrouwenplein lijkt dus nogal op zo'n site als women.com - ook het vrouwenplein heeft verwijzingen, chatgroepen en bulletin boards - maar wat er in die structuur zit is volstrekt anders. De zijwegen leiden ons bijvoorbeeld naar sites over vrouwen en politiek, naar feministische online tijdschriften en naar feministisch plezier, zoals bijvoorbeeld de site 'vrouwen met baarden' die ik u niet wil onthouden. In de discussiegroepen kunnen we onder andere praten over het diversiteitbeleid van de gemeente Amsterdam, over vrouwen met HIV en aids, of over een-ouder gezinnen. Tinne's bar, de chatruimte van het Vrouwenplein, wordt helaas slecht bezocht. Het genderscript van de Digitale Stad is duidelijk feministisch, en het leuke is dat het een heel divers feminisme is waarin geen lijn te ontdekken is. Dat geldt voor al het feminisme op het Internet: er is een levendige subcultuur, maar het is verspreid en soms moeilijk te vinden. Via women.com en haar collega's kom je er in elk geval niet; de zoeksleutel 'feminisme' leverde in women.com slechts 36 pagina's op uit een totaal van meer dan 100.000 .

\section{Grommende meisjes}

Zowel bij de traditionele sites zoals women.com, als bij de feministische sites, zien we eigenlijk een herhaling van bestaande genderpraktijken, alleen dan via een ander distributiekanaal. Dat andere distributiekanaal heeft een belangrijke extra dimensie van interactiviteit waardoor de mogelijkheid ontstaat tot nieuwe en uitgebreidere netwerken van vrouwen. Desalniettemin zijn deze nieuwe eigenschappen ingekaderd in de relatief bekende raamwerken van traditionele vrouwelijkheid in al haar variaties en feminisme in al haar verscheidenheid en daarom kunnen we in deze twee gevallen nauwelijks spreken van een genderscript dat eigen is aan het Internet. Dat is al veel meer het geval bij sites en e-zines die zich verenigd hebben in de portal Chickclick waar geekgrrls, bitches, riotgrrls, guerilla grrls, nrrdgrrls en andere cybergrrls zich uitleven en die door Marianne van den Boomen (1997:15) getypeerd zijn als 'grommende 
meisjes'. Kenmerkend voor dergelijke sites is dat ze net zo min iets met feminisme te maken willen hebben als met traditionele genderpatronen. Om een parallel buiten het Internet te trekken, het is een beetje girlpower op het net waarbij een voor het net specifieke veelvoud aan diverse vormgeving, inhoud en stijl te vinden is die gekenmerkt wordt door een humoristische toon en een fascinatie met populaire cultuur. Ook voor de chickclick-achtige sites geldt echter dat ze richting traditionele sites opschuiven zodra ze commercieel interessant worden (Van den Boomen, 1997).

De daadwerkelijke uitbraak uit bestaande genderscripts vindt plaats in de ondergrondse speelruimtes van het Internet, de zogenaamde Multi-User Dungeons of Domains, ook wel kortweg MUDs genoemd.

\section{Experimentele scripts}

Een MUD is een spelletje dat geheel en al gebaseerd is op de uitwisseling van woorden tussen deelnemers; er komt geen beeld aan te pas. Met woorden worden verschillende ruimtes, situaties en personen beschreven, en via tekstcommando's besta en speel je in een MUD. Er bestaan talloze MUDs; onder de Digitale Stad zit er bijvoorbeeld een en die heet heel toepasselijk Metro. Een gebruikelijke tweedeling wordt gemakt tussen avonturenMUDs waar het doel is om monsters op te sporen en te

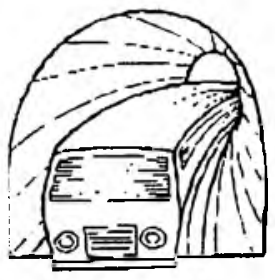

verslaan, en sociale MUDs waar het doel is om mensen te ontmoeten en nieuwe gemeenschappen te bouwen. In toenemende mate worden MUDs ook in onderwijssituaties gebruikt om een soort virtueel klaslokaal te maken. Wanneer iemand toegang zoekt tot een MUD, vraagt het systeem om een naam op te geven waaronder je in de MUD wilt opereren en om een karakterbeschrijving te geven van het personage dat je bent. De keuze daarvan is geheel willekeurig en kan overeenkomen met je naam en karakter in de echte wereld, maar je kunt ook een geheel andere identiteit aannemen: het wisselen van sekse is bijvoorbeeld heel gebruikelijk, maar je kunt ook als een 'zwerm bijen' of als 'Laurel en Hardy' inloggen (Bruckman, 1993), of als kikker die zomaar wat rond komt springen. De eerste en nog steeds de grootste MUD is een Amerikaanse genaamd LambdaMoo waarin duizenden spelers actief zijn, zij het niet allemaal tegelijkertijd. Het zijn dergelijke MUDs die het Internet een reputatie hebben gegeven een laboratorium van sekse-identiteiten en verhoudingen te zijn. Vrouwen doen zich regelmatig als man voor, mannen doen zich 
andersom als vrouw voor. We zouden daarom kunnen zeggen dat in de MUDs experimentele genderscripts ingeschreven zijn. Amerikaanse wetenschappelijke experimenten suggereren dat mannen in dergelijke virtuele sekseveranderingen individualistisch en dominant gedrag loslaten en zich sociaal en ondersteunend ten opzichte van anderen opstellen (Jaffe et al., 1995). Er zijn daarnaast een aantal individuele verhalen van mannen die zich pas in de MUD in de gelegenheid voelen gesteld om hun zachte en zorgzame kanten te laten zien. Dergelijke spelletjes met sekseidentiteiten zijn aanleiding voor diverse wetenschappers om hoge verwachtingen te hebben van de manier waarop het Internet de sociale verhoudingen tussen mensen zou kunnen democratiseren. Zo zegt een Amerikaanse onderzoekster: "De kans om aan de grenzen van sekse, ras en leeftijd te ontsnappen, creëert een interactief spel waarin geen vaste regels bestaan met uitzondering van de regels die door de deelnemers zelf worden opgesteld." (Reid, 1991). MUDs worden door sommigen beschouwd als een postmoderne utopische ruimte waarin de bestaande maatschappelijke scheidslijnen en tegenstellingen zijn opgehouden te bestaan, en waarin nieuwe gemeenschappen met nieuwe regels en culturen ontstaan. In het belangrijkste boek over het effect van dergelijke spelletjes op individuele identiteiten, getiteld Life on the screen, zegt Sherry Turkle (1995) dat MUDs mensen een nieuw instrumentarium bieden om over zichzelf, over hun eigen sekse en over sekse in het algemeen na te denken: "MUDs hebben bewezen dat ze een basis bieden voor een in daadwerkelijke handelingen gebaseerde filosofische praktijk die functioneert als een vorm van bewustwording en bewustmaking van genderissues" (Turkle, 1995:214). De MUDs bieden een fysieke en concrete vertaling van de abstracte, postmoderne opvattingen over meervoudige en gefragmenteerde identiteiten, aldus Turkle.

Desalniettemin gebeurt er in MUDs ook veel van hetzelfde.

De Amerikaanse systeembeheerder van LambdaMoo, Pavel Curtis, die het gedrag van zijn spelers jarenlang van nabij kon observeren, zegt bijvoorbeeld dat sociaal gedrag in de MUD vaak een directe afspiegeling is van gedrag in het echte leven (Curtis, 1992). In LambdaMoo heeft bijvoorbeeld ooit een virtuele verkrachting plaatsgevonden waarbij een mannelijk personage via programmeertrucs een vrouwelijk personage gevangen hield (beschreven in Turkle, 1995:250-254). Niet voor niets voelen vrouwen daarom vaak de noodzaak zich als man voor te doen, ook om onschuldiger vormen van seksisme te ontlopen. Zo zegt een vrouwelijke speler die zich ergert aan de mannelijke personages die steeds maar aanbieden om haar te helpen: "Wat ik raar vind, is de misvatting dat vrouwen niet in MUDs kunnen spelen, dat ze daar geen puzzels kunnen 
oplossen, dat ze niet eens 'kill monster' kunnen intikken, zonder hulp' (geciteerd in Bruckman, 1993). Dezelfde Pavel Curtis zegt ook dat de MUDs voor een deel bevolkt worden door jonge jongens die een heel stereotype beeld van vrouwen als langbenige, rondborstige, blonde seksobjecten construeren. "Dat komt in feite zo vaak voor", zegt Curtis, "dat de volkswijsheid van de MUD zegt dat als je zo iemand tegenkomt, het bijna per definitie een man is" (Curtis, 1992). Daarnaast blijkt dat het wisselen van sekse ook hele praktische kanten heeft voor de MUD-speler: in een kleinschalig Amerikaans onderzoek naar gender bending in spelletjes, zegt $60 \%$ van de mannelijke spelers dat ze een vrouwelijk personage kiezen omdat het hen voordeel geeft bij het spel: vrouwen zijn bijvoorbeeld sneller, moeilijk te zien en te raken naar het schijnt en andere spelers behandelen vrouwen beter dan mannen (Wright, 2000).

Het onderzoek naar MUDs waar ik nu uit geput heb en dat voor een deel veralgemeniseerd kan worden naar algemene Internet-chatpraktijken, suggereert - ondanks de tegenwerpingen - een duidelijk experimenteel genderscript waarin voorschriften van mannelijkheid en vrouwelijkheid niet meer vastliggen en al spelende van nieuwe invullingen kunnen worden.voorzien. Het heeft echter als nadeel dat het vrijwel uitsluitend op Amerikaanse gegevens is gebaseerd. Amerika heeft een specifieke eigen gendercultuur en daarmee zullen spelers ook een andere behoefte of noodzaak voelen tot gender bending dan spelers in een Nederlandse MUD zouden doen. Bovendien is het onderzoek vooral gestoeld op de ervaringen van de zogenaamde early Internet adapters: jonge mannelijke studenten van technologisch georiënteerde universiteiten zoals het MIT. Hun ervaringen, tezamen met die van enkele andere spraakmakende early adapters zoals bijvoorbeeld verzameld in het Amerikaanse on- en offline magazine Wired en de Amerikaanse online gemeenschap The Well, domineren de wetenschappelijke en maatschappelijke discussie over de mogelijkheden en onmogelijkheden van het Internet (Valovic, 2000). Het is echter de vraag of deze ervaringen van early adapters zo indicatief zijn voor de ervaringen van meer alledaagse Nederlandse Internetgebruikers en voor de manier waarop zij al of niet met genderidentiteit experimenteren. Ik heb mij daarom voorgenomen om in het kader van de Opzij Leerstoel daar onderzoek naar uit te laten voeren en zal in het bijzonder kijken naar Nederlandse MUDs, chatlines en homepages. Daartoe heb ik samen met mijn collega professor Maaike Meijer een aanvraag bij het NWO programma Maatschappij en Elektronische Snelweg ingediend. 


\section{Afsluiting}

Ik heb $\mathrm{u}$ in grote lijnen enkele aanwezige genderscripts op Internet laten zien, om inzicht te krijgen in de diverse manieren waarop gebruikers en gebruiksters geconstrueerd worden: ik heb traditionele, feministische, 'grommende meisjes' en experimentele genderscripts laten zien (Van Zoonen, 2000a).We zijn daarbij een aantal virtuele vrouwen tegengekomen: een traditionele consument die haar tijd graag besteedt aan shoppen en chatten. Diverse virtuele feministes, waaronder vrouwen met baarden. Riotgrrls, geekgrrls, nerdgrrls en andere grrls. Sterke vrouwen die de favoriete fantasie blijken te zijn van mannen in de MUDs en andere online spelletjes. Maar we kwamen ook de virtuele seksgodin in de MUDs tegen, die oneindig veel zusters heeft in de talloze pornosites op het net. Als we op deze virtuele vrouwen moeten afgaan, dan zetten enerzijds oude sekseverhoudingen zich onverminderd voort op het Internet, om in termen van het structuurrapport van de Opzij Leerstoel te spreken. Anderzijds creëert het Internet echter nieuwe kansen voor een herformulering van gender, al lijkt het er wel op dat die herformulering in de hoekjes en gaatjes van het Net plaatsvindt, en niet in de in toenemende mate door e-commerce gedomineerde mainstream.

Het Internet zelf biedt dus tegenstrijdige opties en een conclusie over de al of niet emanciperende, dan wel bevrijdende krachten van het Internet, kan alleen maar liggen in een analyse van concrete gebruikspraktijken. Virtuele vrouwen zijn van belang voor die praktijken, omdat ze gebruiksen interpretatiekaders aanbieden waarmee men zich onvermijdelijk te verhouden heeft. Reëel bestaande vrouwen zullen bij tijd en wijle ongetwijfeld wel even in die rol van traditionele consument, sterke vrouw of misschien zelfs seksgodin stappen, maar ze zullen ook daaraan tegenstrijdige gebruiks- en interpretatiepatronen vertonen. Wat dat betreft is de situatie niet anders dan bij televisie of film, waar gebruik en interpretatie van de tekst voor een deel gestuurd worden door de eigenschappen van die tekst, maar gebruikers talloze tegendraadse interpretaties kunnen produceren (cf. Hall, 1973; Van Zoonen, 1994) die afhankelijk zijn van de specifieke context waarin teksten gebruikt worden. Zelfs het lezen van de Boeketreeks en van vrouwenbladen kunnen momenten van verzet herbergen zoals Janice Radway en Joke Hermes zo mooi hebben laten zien, en wie weet veranderen de gebruiksters van women.com hun cellulitis chatline ook wel in een bolwerk van het antischoonheidsideaal. Een tweede onderzoekslijn die ik daarom in het kader van de Opzij Leerstoel wil stimuleren betreft het onderzoek naar concrete gebruikspraktijken en interpretaties van het Internet door alledaagse, 
doorsnee gebruikers, mannen en vrouwen, en naar de manier waarop die gebruikspraktijken inspireren tot nieuwe genderverhoudingen. Uit een eerste etnografische verkenning die ik onder 36 jong volwassenen heb gehouden, blijken voorlopig geen duidelijke sekseverschillen in gebruik en interpretatie van het Internet. Voor vrouwen en mannen vormen e-mail, chat en andere vormen van communicatie de belangrijkste redenen om Internet te gebruiken. Bovendien zijn vrouwen en mannen eensluidend in hun oordeel over Internetcommunicatie als inferieur aan echte, menselijke, face-to-face communicatie. De verbinding Internet $=$ communicatie $=$ vrouwen $=$ vrouwelijkheid vind $\mathrm{ik}$ bij deze groep in elk geval niet, en wat deze voorlopige resultaten suggereren is dat een dergelijk beeld - of het nu van feministes of van marketeers komt - niet alleen vrouwen stereotypeert, maar mannen idem dito veroordeelt tot een harde, zakelijke, efficiënte Internetstijl die de hunne niet hoeft te zijn (Van Zoonen, 2000b; zie ook Bergman \& Van Zoonen, 1999).

Ik ben hiermee aan het einde gekomen van mijn uitleg over de diverse onderwerpen die opdoemen in het kader van gender en multimedia, in het bijzonder met betrekking tot het Internet. Mijn onderzoek zal zich concentreren op gender bending op het Net en op de alledaagse seksespecifieke gebruikspraktijken van het Net. Het is daarbij erg verheugend dat $\mathrm{ik}$ dat onderzoek heb mogen inpassen in het multidisciplinaire onderzoeksprogramma van de Universiteit Maastricht, dat onder de titel Infonomie de diverse maatschappelijke aspecten van de informatiemaatschappij onderzoekt. Ik ben de collega's Luc Soete en in het bijzonder Rita Walczuk erkentelijk voor de plezierige samenwerking in dat programma. Daarnaast wil ik de collega's van het Centrum voor Gender en Diversiteit bedanken voor hun warme collegialiteit en intellectuele energie waar $\mathrm{ik} \mathrm{mij} \mathrm{wekelijks} \mathrm{door} \mathrm{omgeven} \mathrm{weet.} \mathrm{Ik} \mathrm{wil}$ vooral de coördinator van het centrum noemen, Chantal Dijkman en haar twee assistenten Danielle Vaessen en Lisanne van Homberg die onnoemelijk veel werk hebben verzet om deze studiedag en deze oratie te doen slagen. Ik wil ook alle collega's, vrienden en familie uit het Westen,

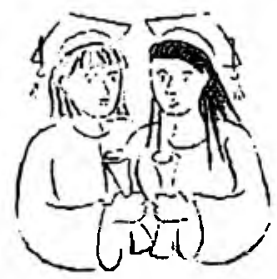

zoals ze hier zeggen, die de verre reis hebben ondernomen bedanken voor hun aanwezigheid. Zoals $\mathrm{u}$ weet, zijn er weinig vrouwen in de top van de wetenschap, om tal van redenen, maar een ervan is dat de combinatie kinderen en carrière ook in de wetenschap nogal onmogelijk blijkt. Ik heb niet alleen twee geweldig leuke kinderen - Tom en Bram - maar ook een aardige carrière; dat is echter in het geheel niet alleen mijn eigen verdienste. Ik hecht er om persoonlijke en politieke reden aan te laten 
zien hoe dat zo kan: flexibele en betrouwbare oppassen en buren, dat helpt om te beginnen: Marijke, Beate, Daniel, Ido, Mireille, Agnes, Lex, Herman en Amalia - bedankt. Mijn ouders hebben mij vroeger naar woord en daad nooit het idee gegeven dat je als meisje mindere of andere dingen zou moeten doen dan als jongen. $k$ heb pas later in de gaten gekregen dat hun voorbeeld heel bijzonder was. Tegenwoordig zijn ze als opa en oma die wekelijks oppassen, nog steeds onmisbaar. Mijn man Jaap Schoufour heeft een vanzelfsprekend enthousiasme voor mijn werk dat veel obstakels uit de weg ruimt: zonder hem had ik mijn aarzeling of ik nu wel helemaal in Maastricht moest gaan werken misschien niet overwonnen. Onze kinderen zijn nog klein, en gelukkig voor hen hier niet aanwezig. Aan hen draag ik deze rede op.

Ik heb gezegd. 


\section{Literatuur}

Ang, I. (1991). Desperately seeking the audience. London: Routledge.

Bergman, S. \& L. van Zoonen (1999). 'Fishing with false teeth. Women, gender and the Internet'. In J. Downey and J. McGuigan (Eds).

Technocities: the culture and political economy of the digital revolution. London: Sage.

Boomen, M. van den (1997). 'Grrls en bitches: postfeministische e-zines'. Lover, jrg. 24(3):8-10.

Brooks, J. (1977). 'The first and only century of telephone literature'. In I. de Sola Pool. (Ed). The social impact of the telephone. Cambridge: MIT Press, p.208-224.

Bruckman, A. (1993). Gender swapping on the Internet. Paper presented at the Internet Society, San Francisco, CA. August.

http://ftp.cc.gatech.edu/pub/people/asb/papers. Retrieved december 24, 1999.

Curtis, P. (1992). Mudding: social phenomena in text-based virtual realities. ftp://lambda.moo.mud.org/pub/MOO/papers/DAIC92. Retrieved december 24, 1999.

Fischer, C. (1992). America calling. A social history of the telephone to 1940. Berkely: University of California Press.

Hall, S. (1973). 'Encoding/decoding'. Reprinted in S. Hall, D. Hobson, A. Lowe \& P. Willis (Eds). (1980). Culture, media, language. London:

Hutchinson.

Hermsen. J. \& A. van Lenning (Eds) (1991). Sharing the difference. Feminist debates in Holland. London: Routledge.

ISOC (1999). 'Helft van alle Nederlanders op Internet.' http://www.isoc.nl. Retrieved november 25, 1999.

Jaffe, J., Y. Lee, L. Huang \& H. Oshagan (1995). Gender, pseudonyms and CMC : masking identities and baring souls. Paper submitted to the 45th Annual Conference of the International Association of Communication. Albuquerque, New Mexico. http://research.haifa.ac.il/ jmjaffe/gender. Retrieved december 24, 1999. 
Jenkins, H. (1999). ' Voices form the combat zone: game grrlz talk back. In J. Cassels and H. Jenkins (Eds). From Barbie to mortal kombat. Gender and computer games. Cambridge: MIT Press, p.328-341.

Martin, M. (1988). "'Rulers of the wires"? Women's contribution to the structure of communication'. Journal of Communication Imquiry, vol.12(2): 89-103.

Martin, M. (1991). Hello Central. Gender, technology and culture in the formation of the telephone system. Montreal: McGill-Queen's University Press.

Moores, S. (1993). Interpreting audiences. The ethnography of media consumption. London: Sage.

Naughton, J. (1999). A brief history of the future. The origins of the Internet. London: Weidenfeld \& Nicolson.

Nua (1998). 'It's an image thing'. Nua Internet Surveys.

http://www.mua.ie/surveys/?f=VS\&art_id $=886595295 \&$ rel=true. Retrieved april $28,2000$.

Nua (1999). 'Six types of women who use the Net'. Nua Internet Surveys. http://www.nua.ie/surveys/?f=VS\&art_id=905355414\&rel=true. Retrieved april 28, 2000.

Nua (2000). 'Men spend longer online at home and work.' Nua Internet Surveys. $h t t p: / / w w w$. nua.ie/surveys/?f=VS\&art_id $=905355677 \&$ rel=true. Retrieved april 28, 2000.

Oudshoorn, N. (1996). Gender scripts in technologie: noodlot of uitdaging? Rede uitgesproken bij de aanvaarding van het ambt van hoogleraar Gender en Technologie aan de Universiteit van twente op donderdag 12 september 1996. Enschede: Universiteit van Twente.

Plant, S. (1998). Zeros and ones. Digital women and the new technoculture. London: Fourth Estate.

Rakow, L. (188). 'Women and the telephone: the gendering of a communications technology.' In C. Kramarae (ed). Technology and women's voices: keeping in touch. New York: Routledge and Kegan Paul, p.207-229. 
Reid, E. (1991). Electropolis: communication and community on Internet relay chat. http://people.wemediaone.net.elizrs.electropol. Retrieved december 24, 1999.

Rommes, E., E. van Oost \& N. Oudshoorn (1999). 'Gender in the design of the digital city of Amsterdam.' Information, Communication \& Society, 2(4):476-495.

Schwartz Cowan, R. (1987). "The consumption junction: a proposal for research strategies in the sociology of technology'. In Bijker, W. , T. Hughes \& T. Pinch (Eds). The social construction of technological systems. Cambridge: MIT Press.

SCP (1999). 'De digitalisering van de leefwereld.een onderzoek naar moderne informatie- en communicatietechnologie en sociale ongelijkheid.' http://www.scp.nl/lezing/13121999/tekst.htm. Retrieved april 28,2000 .

Sherman, A. (1998). Cybergrrl. A woman's guide to the world wide web. New York: Ballantine Books.

Silverstone, R. \& E. Hirsch (Eds) (1992). Consuming teclmologies. Media and information in domestic spaces. London: Routledge.

Spender, D. (1995). Nattering on the net. Women, power and cyberspace. North Melbourne: Spinifex Press.

Turkle, S. (1995). Life on the screen. Identity in the age of the Internet. New York: Simon and Schuster.

Valovic, T. (2000). Digital mythologies. The hidden complexities of the Internet. New Brunswick: Rutgers University Press.

VODW (1999). 'Internet: it's a woman's world'. VODW Making Waves New York. http://www.vodw.com/makingwaves/. Retrieved april 28, 2000.

Wright, K. (2000). 'Gender bending in games'. $h t t p: / / w w w . w o m e n g a m e r s . c o m / a r t i c l e s / g e n d e r . h t m l$. Retrieved april 28, 2000.

Zoonen, L. van (1994). Feminist media studies. London: Sage. 
Zoonen, L. van (2000a). The gendered meanings of the Internet. Mainstream, feminist and experimental scripts. Keynote address prepared for the British Media, Communication and Cultural Studies Association, Sheffield.

Zoonen, L. van (2000b). Een computer kan niet knuffelen. Paper gepresenteerd op het congres Communicatiewetenschap: de groeistuipen voorbij. Universiteit Twente, Enschede. 
